\title{
SENTIMENTOS E REAÇŌES DO ALUNO DE ENFERMAGEM ANTE ALGUMAS SITUAÇÕES RELACIONADAS À SEXUALIDADE INFANTIL
}

\author{
Moneda Oliveira Ribeiro*
}

RIBEIRO, M.O. Sentimentos e reações do aluno de enfermagem ante algumas situaçōes relacionadas à sexualidade infantil. Rev. Esc. Enf. USP, São Paulo, 23(2): - ago. 1989.

Neste estudo realizou-se um inquerito onde a autora visou obter elementos que permitissem conhecer o preparo do estudante de enfermagem para prestar assistência de enfermagem d criança e ao adolescente no que diz respeito d sexualidade infantil. A motivação em obter estes dados decorreu da falta de participação verbal do aluno ao ser abordada a sexualidade do adolescente em sala de aula, impossibilitando identificar seus sentimentos e reaçöes ante situaçōes relacionadas ao tema.

UNITERMOS: Estudantes de enfermagem. Sexualidade infantil.

\section{INTRODUÇĀO}

Discutir sexualidade é falar sobre história, política, religião, psicologia, diferenças raciais e culturais, valores morais, ética, crenças, tabus e educação.

A sexualidade está presente em todos esses fatores ou todos esses estāo presentes na sexualidade e, no entanto, pouco se faz para a orientação e educação sexual.

TAVARES 8 comenta que nos últimos anos houve uma explosāo do "sexo" através de revistas, filmes, pornografias, sendo essas informaçōes utilizadas de maneira nāo muito idônea, para fins de exploraçāo comercial. Para a autora, essas informações confundem os jovens, levando-os a banalizar o sexo, tornando-o despersonalizado, sem relacionamento pessoal, não havendo ligação entre sexo e afetividade.

O sexo e a educação sexuai são vistos como tabu, na familia e na escola. Esses aspectos, no entanto, sāo ignorados e atualmente está sendo incentivado e divulgado o relacionamento sexual através dos meios de comunicação.

\footnotetext{
* Enfermeira. Auxiliar de cosino do Departamento de Enfermagem Materno-Infantil e Psiquiáurica da Escola de Enfermagem da USP - disciplina Enfermagem Pediátrica.
} 
FUCS ${ }^{5}$ alerta quanto as implicaçōes político - econômicas e religiosas sobre a sexualidade dizendo que as normas de regulação sexual dependem dos interesses do sistema econômico vigente. Diz também que na sociedade de consumo em que vivemos, a sexualidade tem sido mercadoria de oferta, a partir de modelos preestabelecidos e, nesta moral/social, há influência da religião que também exerce este controle.

Em função de todas essas implicações sociais, vê-se, cada vez mais, a importância de incentivar a educação e orientação sexual. A quem compete esse papel? Seriam os pais responsáveis pela educação sexual da criança e do adolescente, se estão embuídos de preconceitos, crenças e valores morais repressivos? E qual é o papel da sociedade nisso? Estão os professores preparados para a educação sexual?

TAVARES $^{8}$ aponta a crescente responsabilidade das escolas de $1^{\circ}$ e $2^{\circ}$ graus em desempenhar funçōes de educaçāo sexual, uma vez que as familias estão delegando, às escolas, essa tarefa de orientação sexual que seria de competência dos pais da criança.

Se professores são produto de um processo educacional carregado de valores morais repressivos tal como os pais, qual a qualidade da orientação sexual no ensino?

EGRY $^{3}$ reaiizou um estudc com professores da Escola de Enfermagem da USP, onde se veriticam as difículdades e receios por parte dos mesmos em lidar com a educaçāo sexual.

CHAFFEE $^{2}$ atirma que estudantes de medicina e enfermagem carecem de formaçāo no campo da sexualidade porque este assunto é pouco explorado nos currículos escolares. Defende a idéia de neles incluir questôes relacionadas a crenças, valores, atitudes e sentimentos sexuais. Lembra, ainda, que enfermeiras defrontam-se com problemas de saúde em várias situações e é essencial que a educação em enfermagem seja baseada em ciências sociais, comportamentais e clínica.

A influência da carência de informação dos estudantes quanto a sexualidade numana é confirmada no relato de WATANABE $^{9}$ at alii, estudantes de enfermagem. Nele, comentam o temor em discutirem assuntos sexuais com um grupo de adolescentes, a quem ministrariam aulas, e a preocupaçāo em levarem a eles idéias desprovidas de preconceitos.

Percebemos neste relato, a dificuldade das alunas de enfermagem em discutir esse assunto com adolescentes, também, devido às experiências delas estarem bem próximas da fase de adolescência.

SALLES $^{7}$ não limita o final da fase de adolescência aos 18 ou 20 anos como alguns autores, para ele esta fase só termina com a independência econômica ou com o casamento. 
A identificação das estudantes de enfermagem com os adolescentes, pode justiticar a reaçāo de constrangimento dos alunos em sala de aula, quando comentamos soore a sexualidade na adolescência. Reação sernelhante constatamos em diversas turmas que cursam a graduação na Escola de Enfermagem da USP. Percebemos que falar sobre sexualidade na adolescência é tocar em assuntos diretamente relacionados à vivência dos alunos, que parecem ir de encontro a uma vivência onde há situações de contlito e, portanto, difícil de falar a respeito. Pressupomos que valores, tabus e preconceitos interferem na forma como o aluno lida com a sexuaiiciade. Esta falta de participação do aluno não nos permite obter elementos para veriüicar se ele está ou nāo preparado para prestar assistência de enfermagem no que diz respeito à sexualidade infantil*.

\section{OBJETIVO}

Identificar quais os sentimentos e reações do aluno de enfermagem ante algumas situaçõs relacionadas com a sexualidade infantil.

\section{ABORDAGEM METODOLÓGICA}

A população deste trabalho compreendeu estudantes da Escola de Enfermagem da Universidade de Säo Paulo, antes de cursarem a disciplina Enfermagem Pediátrica I. Solicitamos a todos os $\mathbf{5 3}$ alunos presentes na sala de aula em março de 1987, para participarem do estudo.

Foi reaiizado um estudo exploratório descritivo, cujo instrumento de coleta de dados consistiu em um questionário (Anexo I), destinado à caracterizaçáo dos alunos e identificaçāo dos seus sentimentos e reaçōes ante três situaçōes relacionadas à sexualidade infantil.

A popuiação foi caracterizada segundo a idade, sexo, estado civil, religiāo, nacionalidade própria e dos pais, naturalidade e fontes de informaçōes sobre sexualidade. Esses aspectos foram investigados porque são elementos capazes de nterierir nas respostas das questões da segunda parte do instrumento, isto $\dot{E}$, as três situaçōes. Esta parte exigia respostas imediatas e pouco refletidas porque as situaçōes apresentadas revelavam um fato inesperado. Assim, nāo foi permitido o conhecimento prévio do instrumento pelos alunos e nem o seu preenchimento em mulisunto posterior, à data e hora marcada.

O tempo utilizado para coleta de dados restringiu-se ao espaço de uma hora para orientação, preenchimento e devolução du questionário.

As categorias indicadas nos anexos ll e ili toram elaboradas de modo a manter as expressōes utilizadas pelos aiunos, ou scja, foram conservados os ter-

\footnotetext{
* sexualidtade infantil - diz res[eito à criança c ao adolescente.
} 
mos empregados para sentimentos, reações e motivos. Em relaçāo às justificativas dadas para as reações, houve alteraçāo apenas na mudança da primeira para a terceira pessoa do singular. Essa modificaçāo deveu-se ao fato de as respostas repetidas por alunos distintos serem expostas nas categorias somente uma vez. Assim, pareceu-Iıos mais fidedigno modilicarmos o pronome pessoal das orações sem alterar as expressões peculiares dos alunos.

\section{APRESENTAÇĀO E DISCUSSĀO DOS RESULT $r$ ĹLOS}

Dos 72 alunos matriculados, responderam ao questionário todos os 53 presentes em sala de aula no dia da coleta de dados.

A maioria dos alunos $(56,60 \%)$, tem de 19 a 21 anos, decrescendo esta percentagem à medida que a faixa etária se eleva até a máxima obtida de 28 anos.

Há predominância do sexo feminino $(94,33 \%)$. Dos 53 ảunos, 2 sāo casados $(3,78 \%)$, os demais $(96,22 \%)$ são soiteiros e apenas um $(1,89 \%)$ tem îilho(s).

Todos os estudantes sāo brasileiros, sendo $90,57 \%$ do estado de São Paulo e 9,43\% de estados das regiōes Nordeste, Sul e Centro-Ceste. Dos procedentes de São Paulo, $71,70 \%$ são da capital, $11,32 \%$ do interior e $7,55 \%$ da Grande Sāo Paulo.

A maioria dos estudantes descende de pais brasileiros $(75,47 \%$ pai e $83,01 \%$ mãe), sencio os pais estrangeiros $(18,86 \%$ pai e $13,21 \%$ mãe) de origem japonesa, portuguesa, espannola, italiana e boliviana.

Quarto à religião, veritica-se predominio da catöiica $(69,82 \%)$, seguida da protestante $(9,43 \%)$ e espírita $(7,54 \%)$.

As tontes de informaçăo sobre sexualidade citadas ioram: livros $(20,45 \%)$, amigos $(20,00 \%)$, professores $(12,45 \%)$, revistas $(11,55 \%)$, familiares $(11,11 \%)$, pais $(10,22 \%)$, parceiros $(8,00 \%)$, médicos $(4,00 \%)$ pornografias $(0,89 \%)$ e outras $(1,33 \%)$ como televisão, cursos para crianças e observação. Observa-se que o recurso numarı mais citado foi "amigos", taivez devido à diversiticação de valores ético-morals cet umá geraçăo à outra, facilitando aos estudantes obterem este conilecimento de pessoas com iaade mais próxima. É interessante lembrar que, em geral, no processo educacional (até que se atinja a idade adulta), a aprendizagem ocorre sob a orientaçāo de adultos.

Quanto às respostas apresentadas em relação à situação 1 , notamos que a maioria $(62,26 \%)$ expressou sentimentos de bloqueio e reaçōes de intervençăo.

Isso demonstra uma dificuldade em lidar com a situação 1 , além de não haver aceitação em relação ao comportamento sexual das crianças por maior parte dos alunos. As reaçōes de conversar com as cıianças, distrai-las ou separá-las, expressam interrupção do processo ù sescoberta da sexuaiidade iniantil. Ainda que 
motivos apresentados como 'poderiam se machucar", tenham a conotação de não prejudicá-los, essa pode ser uma forma disfarçada e inconsciente, por parte do aluno, de intervir contrariamente à ação delas.

Devido à iaade próxima das crianças, ambas têm a possibilidade de romper a maunpulaçäo mútua se sto estiver provocando dor. O aduito que aceita esta situação, pode ajenas íicar atento para evitar que se macnuquem, se for o caso, e intervir somente se elas reagirem demonstrando recusa ao procedimento. Quanto ao risco de "ficarem doentes com a manipulaçāo de mâos sujas", pode-se fazer higiene das crianças após o contato eletuado.

PIZZATTO $^{6}$ defende esta questāo da seguinte forma: a curiosidade sexual é natural, espontânea e fisiologica, sendo dispensada a espionagem por parte dos responsáveis, tentando sondar, antecipar e prever reaçôes da criança.

Năo pretendemos estabelecer padrōes de comportamento aos alunos, mas levá-los a reflexão para uma tomada de consciência de seus valores e, assim, agir de movio que julguem mais adequado, tendo a certeza de que sua reação tem um objetivo nítido de atender a intencionalidade de seu pensamento, ceixixando explícito às crianças as razōes dos limites que lhes são impostos. Dizer a elas "para não fazerem isso, não é correto", não é adequado. Este argumento é um valor que a pessoa que intervem possui. É mais respeitoso à formação das crianças, dizer-lhes que näo gosta do que estão fazendo, se for o caso, ao invés de fechar a elas a possibilidade de opção, quando se diz que não devem fazer isso. Educaçāo infantil precisa ser de modo tal que a criança seja um elemento ativo nesse processo, ou seja, ela toma conhecimento dos valores de quem cuida dela, mas possui o livre arbitrio de optar se aceita ou não os valores de outrem, ou de criar seu próprio valor moral.

PIZZATTO ${ }^{6}$ salienta a dificuldade de estabelecer frases ou atitudes estereotipadas à cada situação, dizendo que não há frases mágicas em educaçāo sexual, e que pais ou orientadores precisam optar por uma alternativa, tendo como base o diagnóstico da situação e do momento.

"Esclarecer as curiosidades das crianças" através do ato de conversar pode ser, também, uma forma disfarçada de interromper o procedimento delas. Na situaçāo 1, as crianças estāo satisfazendo suas curiosidades através do contato manual, da visualizaçāo e interrelacionamento entre elas, e não solicitam a presença de adultos para esclarecimentos.

TAVARES $^{8}$ afirma que as informaçōes devem ser dadas aos poucos, não além da solicitaç̄̇o da criança e só quando estiver apta a recebê-las, a pedi-las por si mesma.

Agir de modo a atender o "proprio pudor", em detrimento da necessidade que a criança sente em satisfazer suas curiosidades sexuais, pode ser uma medida repressiva, às vezes inconsciente, por parte do adulto. 
TAVARES $^{8}$ comenta que a orientaçāo sexual de crianças demanda preparo, necessidade de "mentalidade aberta", ausència de preconceitos e de problemas que possam influenciar no desenvolvimento das atividades educacionais.

Conversar com as crianças "para saber se só se tratava de curiosidade ou se esse contato sexual já lhes era familiar", tem a conotaçāo implícita do aluno estar considerando a possibilidade desse contato sexual ser anormal.

Segundo a psiquiatra e sexóloga $\mathrm{FUCS}^{5}$, a vida sexu i da criança é encarada como preocupante e sinal precoce de tara, daí ser reprimicia pela família, escola e adultos que a cercam. A autora constata que a criança faz as pessoas reviverem sua situação sexual, muitas vezes conflituosa, resultando na repressăo à criança que, por sua vez, é incentivada pelo contexto social. $\mathrm{O}$ adulto comumente encontra mecanismos sutis de repressão à sexualidade infantil.

Qual a compreensão que o aluno possui de "educação sexual", quando ressonde que o motivo de sua reação de intervenção (separá-las ou distraí-las) "seria o começo de uma educação sexual'?

BERNARDI ${ }^{1}$ alerta para o risco de "educaçāo sexual" como uma forma de controle sobre o comportamento sexual, criando um problema, ao invés de solucioná-lo, dizendo: Se uma criança aprende sozinha a ler e a escrever todos se alegram com isso, mas se uma criança aprende sozinha o que é o seu corpo, o seu sexo, o seu prazer, e por isso também o amor, ficam todos horrorizados. Queremos nós mesmos ensinar-lhe, e do nosso modo. Assim, inventamos a educação sexual. Ou melhor, inventamos o problema da educação sexual.

A educação sexual passa a ser problema quando se impōe padrōes de comportamento, em geral condizente com o sistema sócio-político vigente, que é repressor sobre as classes sociais exploradas.

BERNARDI ${ }^{l}$ alerta para o fato de que repressão sexual e repressāo sóciopolítica săo como irmās gêmeas; respeitar a liberdade sexual da criança e conseqüentemente reconhecê-la, põe em crise a sexualidade aceita pelo sistema, a sexualidade adulta, única considerada normal.

$O$ aluno que apresenta o motivo de sua reaçāo de intervenção como "isso nāo se faz nessa idade, mas sim quando crescer", demonstra a aceitaçāo deste comportamento somente na fase adulta. Pode-se concluir, então, que há uma projeção da sexualidade adulta sobre a infantil. Isso está mais evidente na resposta do estudante que reage à situação 1, dizendo que "explicaria as diferenças sexuais às crianças", no entanto, nessa situaçāo, nāo está especificado se elas são de sexos diferentes, assim, não há dúvida que o aluno vê a sexualidade infantil como interesse pelo sexo oposto, como ocorre no adulto, e não apenas como um processo de descoberta de seus corpos. É preciso discemir nossos valores dos demais, para nāo haver interpretaçōes errôneas das açōes de outrem e, com isso, reagirmos repressivamente. 
Verificamos nas justificativas da situaçāo 1, uma preocupaçāo dos estudantes em "agir com naturalidade". Entretanto, esta açāo aparece nas categorias das reaçōes de intervençāo, permissão e nas de ação nāo observável (anexo III). Com isso, observa-se que não há consenso entre os estudantes, de qual é o comportamento que caracteriza uma ação natural. Pode-se, contudo, supor que "agir com naturalidade" significa "não brigar para não criar medo nas crianças", "orientar e não repreender", "não traumatizá-las" e "não mostrar que estäo fazendo algo errado", uma vez que essas experiências vêm escritas junto ao "agir com naturalidade". Parece-nos, entāo, que "agir com naturalidade" é o que "não se deve fazer", ou seja, é evitar agressōes físicas e verbais às crianças, mas isso não impede de intervir no comportamento delas.

Notamos elevado número $(20,76 \%)$ de estudantes que nāo expressaram sentimentos em relaçāo a situação 1 . Isso pode refletir a dificuldade que os estudantes possuem em identificar e expressar seus sentimentos, ou seja, de se auto-conhecerem ou reconhecer seus valores éticos-morais e religiosos.

Houve um número significativo $(24,52 \%)$ de estudantes com reaçöes de permissividade à situação 1 . Estes 13 estudantes incluídos nesta categoria, apresentaram sentimentos de bloqueio $(9,43 \%)$, não bloqueio $(9,43 \%)$ e não expressos $(5,66 \%)$. Isso demonstra que apesar de alguns alunos terem sentimentos de bloqueio, permitiiam a atuação das crianças.

Os estudantes que manifestaram sentimentos de não-bloqueio $(16,98 \%)$, estāo divididos entre as reaçōes de intervençāo $(7,55 \%)$ e de permissāo $(9,43 \%)$. Com isso, é possivel perceber que alguns reagem intervindo no comportamento das crianças, apesar de exprimirem sentimentos de nāo-bloqueio.

Quanto às respostas apresentadas em relação à situação 2, notamos que a maioria $(64,15 \%)$ dos estudantes expressa sentimentos de bloqueio, mas as reaçōes mais manitestadas $(64,15 \%)$ foram as de permissão. Isso demonstra que apesar da situaçäo 2 causar sentimentos de bloqueio, os estudantes aceitam o comportamento do adolescente, embora haja motivos apresentados como "seria uma forma de ignorar o problema (ou fugir dele)", ou fazendo alguma ressalva como "é um momento dele e normal, mas não deve ser estimulado".

Os integrantes da população da pesquisa de pequena EGRY ${ }^{4}$, demonstratam ser mais favoráveis à masturbação para o homem do que para a mulher e a criança. Os resultados mostraram, também, maior percentagem de alunos sem opiniāo formada quanto a masturbação infantil. A autora, no entanto, alerta que isto é paradoxal, uma vez que esta prática é considerada normal no desenvolvimento infantil. Assim, EGRY ${ }^{4}$ supōe que a opiniāo desfavorável seja devida ao incômodo sentido pelo adulto ao presenciar esta prática em crianças

Novamente, um número elevado $(18,87 \%)$ de alunos não expressaram sentimentos em relaçāo a uma situaçăo que pode melindrar os valores ético-morais e religiosos dos estudantes. 
Constatamos reaçües de hesitação $(16,98 \%)$, nas quais, de acordo com os motivos de disfarçar, fingir nāo ver e hesitar em entrar (anexo III), mais parece existir a intençăo, por parte dos alunos, de não interferir no procedimento do adolescente do que, propriamente, não saber como agir nesta situaçāo.

É expressivo, também, a porcentagem de estudantes $(15,10 \%)$ que manifestam reaçōes de intervençāo. Alguns alunos deixam patente a rejeição em relaçāo a prática do adolescente, justificando com "não é algo para se fazer no hospital", ou "seria bom esclarecer certos pontos", ou fazendo perceber sua presença "assim ele iria parar de se masturbar."

A expressão "agiria com naturalidade" aparece nas quatro categorias de reações. Com isto, verifica-se que existe uma preocupação, por parte do aluno, em encarar á sexualidade infantil como normal; no entanto, há divergência entre as açōes consideradas naturais. Mesmo as reaçōes opostas (de intervenção ou permissão) foram enfocadas pelo aluno, como naturais. Pode-se inferir, então, que existe uma preocupaçăo por parte dos estudantes de não serem agentes repressivos da sexualidade infantil. Falta-lhes, contudo, perceber que algumas açôes são altamente repressivas, embora sejam muito sutis.

Quanto às respostas apresentadas em relação à situação 3, observamos uma porcentagem elevada $(73,59 \%)$ de sentimentos que expressam bloqueio ao lidar com esta situação. As reações, no entanto, apresentam-se bem diversificadas, havendo um equilibrio entre as reações de interrupção do exame físico e as de hesitação (20,76\% em ambas) e uma proporção um pouco maior para as reaçōes de continuidade do exame físico $(33,96 \%)$ e as de ação não observável $(24,52 \%)$.

A diversidade nas respostas das reaçöes expressas pelos alunos demonstra a inexistência de senso comum que determine a conduta a ser tomada. Isso está mais evidente nos seguintes motivos, das reaçōes de interrupção e de continuidade do exame físico respectivamente, "permanecer ao lado ou fingir que nada aconteceu seria pior", em relação a "para esconder o que sentiria e não se mostrar abalada, fingindo que nada aconteceu".

"Postura profissional", é uma expressão empregada pelos estudantes que aparece em todas as categorias de reações da situação 3, exceto na de interrupção do exame físico. Assim, é possível perceber uma compreensão do significado de "postura profissional" entre os estudantes, mas esta nāo leva a uma mesma conduta.

De acordo com as justificativas manifestadas como deve-se tomar uma postura profissional de que nada aconteceu ou para não perder a pose, isto é a posição profissional, examinaria normalmente"; ou "para contornar o problema, seria uma forma de manter a postura profissional, encarando o fato como um outro qualquer"; pode-se concluir que "postura profissional" tem a conotação de "disfarçar" ou de "esconder o que sente". 
Essa preocupaçāo de ocultar os sentimentos aparece em outras justificativas como "procuraria nāo demonstrar a inibição sentida" ou "devemos tentar nos controlar mostrando que o ocorrido não é vergonhoso para que o paciente não se sinta culpado".

$\mathrm{O}$ que faz os alunos pensarem que ocultar seus sentimentos é a solução para enfrentar a dificuldade da situação? O que os faz concluírem que o paciente sentir-se-ia culpado se demonstrasse estar envergonhado? Estaria o aluno culpando o paciente, mas resiste em admitir isso?

Segundo FUCS ${ }^{5}$ todos nós temos nossa personalidade intensamente influenciada pela formação familiar que nos transmite valores e padrões da sociedade, repletos de tabus e preconceitos quanto a sexo. Conseqüentemente tais preconceitos repercutem na formação profissional do estudante

$\mathrm{CHAFFEE}^{2}$ defende que enfermeiros precisam expandir seus conhecimentos sobre a sexualidade para maior tranquilidade nas discussōes e maior consciência ao examinar atitudes pessoais, valores e preconceitos, e assim, desenvolver padrões de comunicação, avaliação e intervenção relativos à saúde sexual.

Se diminuir o desconforto dos estudantes nas discussōes sobre sexualidade, talvez haja maior conscientizaçāo de seus valores morais, conseqüentemente maior auto-conhecimento e diminuição da percentagem de alunos que não expressam sentimentos $(16,98 \%)$.

\section{CONSIDERAÇŌES FINAIS}

A diversidade de respostas da população estudada conduz à necessidade de discutir o assunto, visando proporcionar oportunidade de crescimento pessoal ao aluno e conseqüente melhora da assistência de enfermagem à criança, e assim, evitar a reprudução de uma educação ideológica repressiva sobre a sexualidade infantil.

Sexualidade humana é um assunto que não se esgota enquanto houver vida, somos sexuados desde o nascimento até a morte. Há ainda muito para se explorar e conhecer em relaçāo a sexualidade infantil.

Pretendemos discutir nossas inferências decorrentes dos resultados obtidos com os estudantes que participaram deste estudo e com os demais que venham a cursar a Disciplina Enfermagem Pediátrica I. Acreditamos que desta forma estaremos propiciando questionamentos a respeito da sexualidade infantil.

RIBEIRO, M. O. Feeling and reactions of underground nursing students some situations related to children' sexuality. 
This work is an investigation which the author intends to obtain subsidies ons preparation of nursing students on children' sexuality to give nursing care to children and adolescents. The motivation to obtain these date came fron absence of participation of students when talking about this topic in class-room. This fact did not make possible to identify feelings and reactions of students to some situations relative to topc.

\section{UNITERMS: Nursing students. Child sexuality.}

\section{REFERÊNCIAS BIBLIOGRÁFICAS}

1. BERNARDI, M. A deseducaçāo sexual. São Paulo, Summus, 1985. $144 \mathrm{p}$.

2. CHAFFEE, M. W. The nursing link in nursing education: sexuality. Imprint, New York, 13(4):43, nov. 1984.

3. EGRY, E. Y. O docente de enfermagem e o ensino dॄ sexual idade humana: ação educativa atraves da pesquisa participante. Sāo Paulo, 1985. 157 p. (Tese de doutorado-Faculdade de Saúde Pública da USP).

4. - Opinião dos graduandos de enfermagem sobre algumas práticas sexuais. Rev. Esc. Enf. USP., Sāo Paulo, $19(1): 55-73$, abr. 1985.

5. FUCS, G. B. A educaçăo e os profissionais que lidam com a saúde e o comportamento humano. Clín. Méd., São Paulo, 2(6): 16-22, ago. 1984.

6. PIZZATO, M. Educação sexual da criança. Rev. Gaúcha Enf. Porto Alegre, 3(1):51-9, dez. 1981 .

7. SALLES, J.M. Adolescência Femina, Rio de Janeiro, 13(1):54-9, jan. 1985.

8. TAVARES, C. A. Orientação sexual para crianças e adolescentes: proposta para formação de enfermeiros como educadores sexuais. Rev. Paul. Enf., Săo Paulo, 5(1):8-11, jan./mar. 1985.

9. WATANABE, G. et alii. Relato de estudantes de enfermagem que ensinam e aprendem com adolescentes. Rev. Paul. Enf., Såo Paulo, 4(3):121-3, jul./ago./set. 1984.

\section{ANEXO I}

I. CARACTERIZAÇĀO DA POPULAÇĀO.

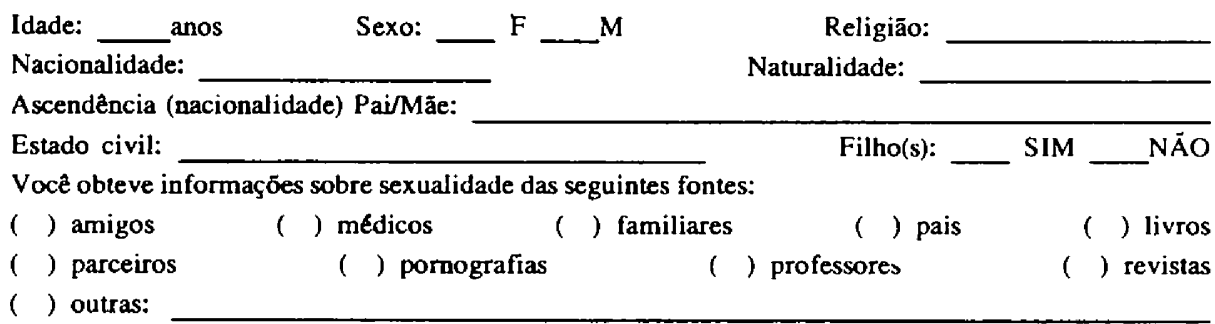

\section{SITUAÇÕES.}

Ao estagiar em uma unidade de internaçăo de um hospital infantil, você poderá encontrar situaçōes semelhantes às descritas à seguir. Leia a situação e responda as questōes o mais sinceramente possível. da outra.

1. Ao entrar em uma enfermaria, você vê duas crianças, de 4 e 5 anos, manipulando os genitais uma 13 anos.

2. Ao entrar em um quarto de isolamento, à noite, você encontra, se masturbando, um adolescente de

3. Você está realizando exame ffsico em um adolescente de 16 anos e, ao examinar seus genitais, ele tem uma ereçảo.

Para cada uma das situaçōes, pergunta-se:

Que sentiria você?

Que faria você? Por que? 
A NEXO II

SENTIMENTOS - SITUAÇŌES 1,2,3

\section{SENTIMENTOS QUE EXPRESSAM BLOQUEIO EM LIDAR COM A SITUAÇĀO}

$\begin{array}{lll}\text { Constrangimento } & \text { Acanhamento } & \text { Expectativa } \\ \text { Surpresa } & \text { Embaraço } & \text { Confusa } \\ \text { Assustada } & \text { Sem jeito } & \text { Frio na barriga } \\ \text { Vergonha } & \text { Sem graça } & \text { Medo } \\ \text { Envergonhada } & \text { Encabulada } & \text { Ansiedade } \\ \text { Culpada } & \text { Intrusa } & \text { Estranha } \\ \text { Intimidado } & \text { Espanto } & \text { Esquisita } \\ \text { Acharia desagradável } & \text { Admirada } & \text { Acharia mais ou menos natural } \\ & \text { Inibição } & \end{array}$

SENTIMENTOS QUE NĀO EXPRESSAM BLOQUEIO EM LIDAR COM A SITUAÇĀO

$\begin{array}{ll}\text { Acharia natural } & \text { Engraçado } \\ \text { Indiferença } & \text { Graça } \\ \text { Comprensāo } & \end{array}$

NĀO EXPRESSAM SENTIMENTOS

Năo respondeu

Nada

Não sei

Vontade de sair

Rev. Esc. Enf. USP, São Paulo, 23(2):3-19. abr. 1989 


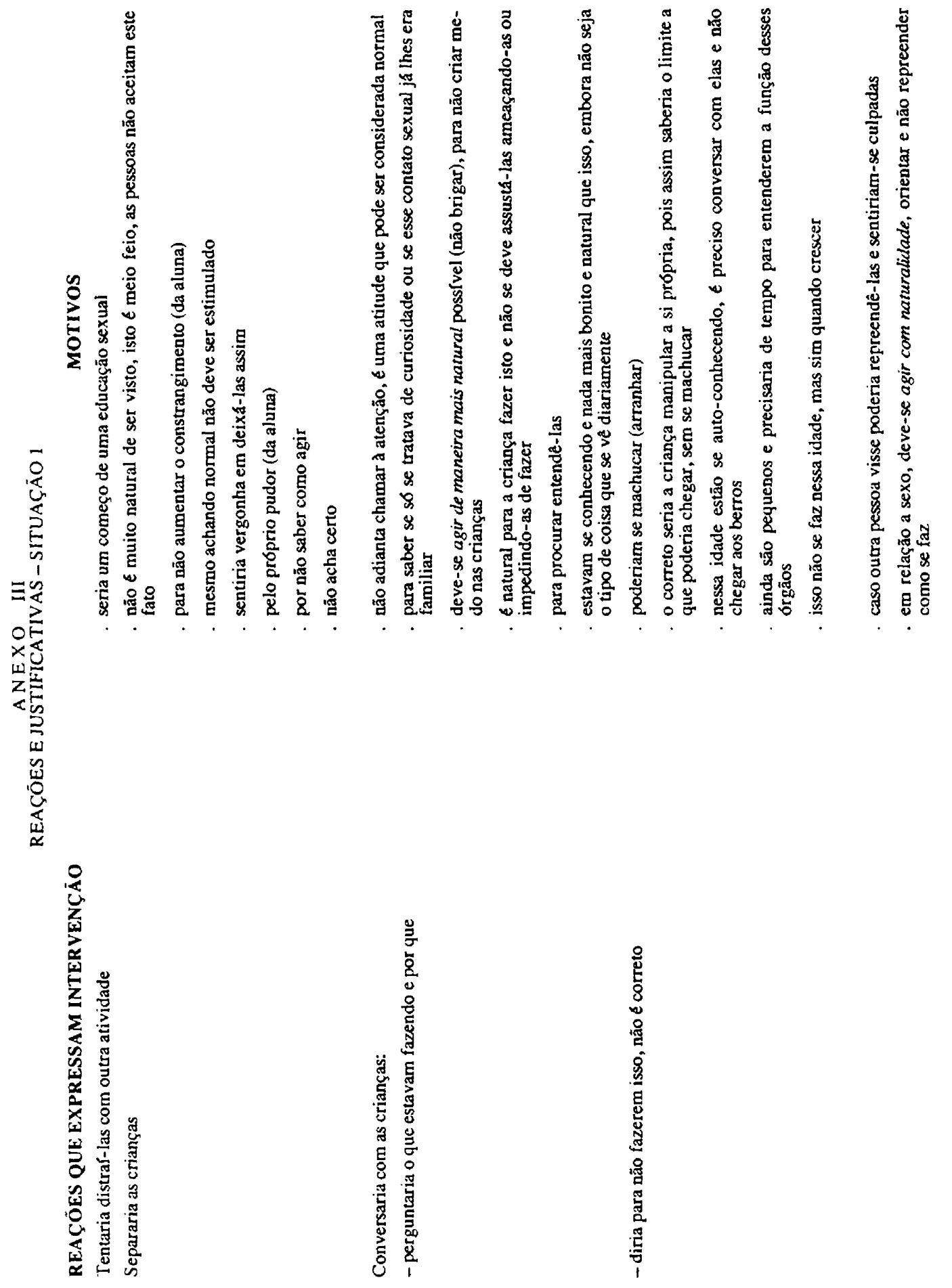



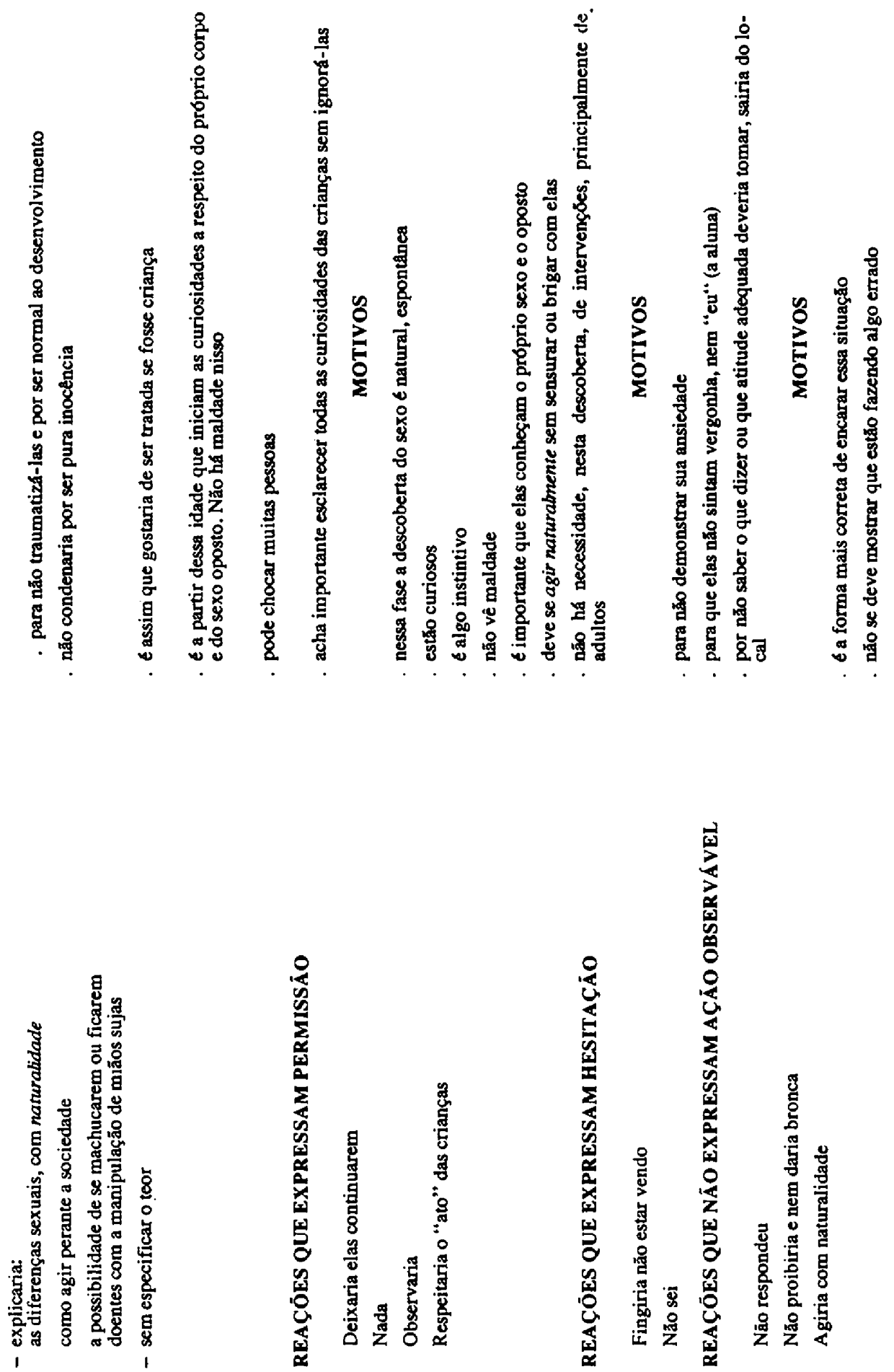

Rev. Esc. Enf. USP, São Paulo, 23(2):3-19, abr. 1989 


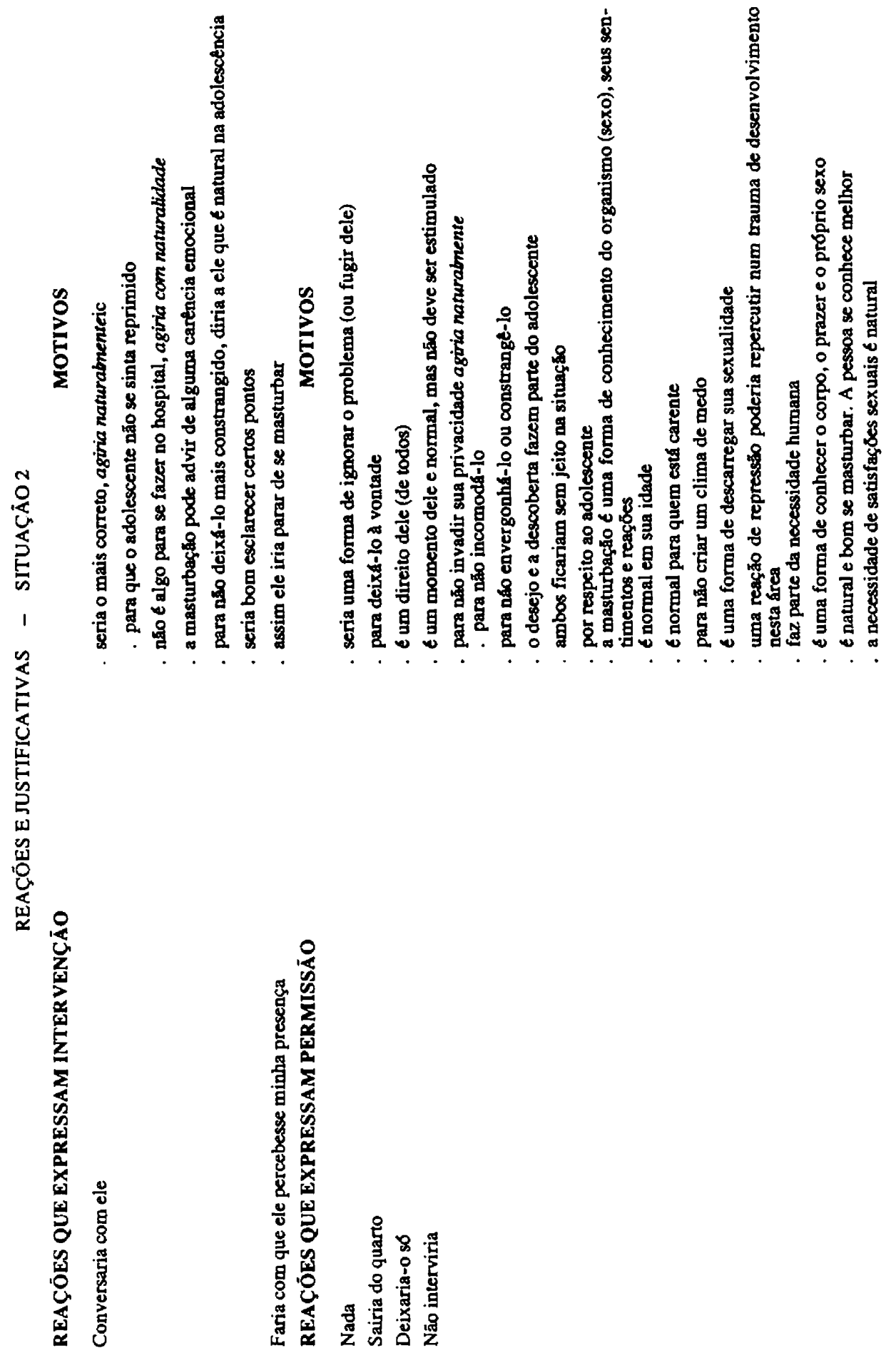



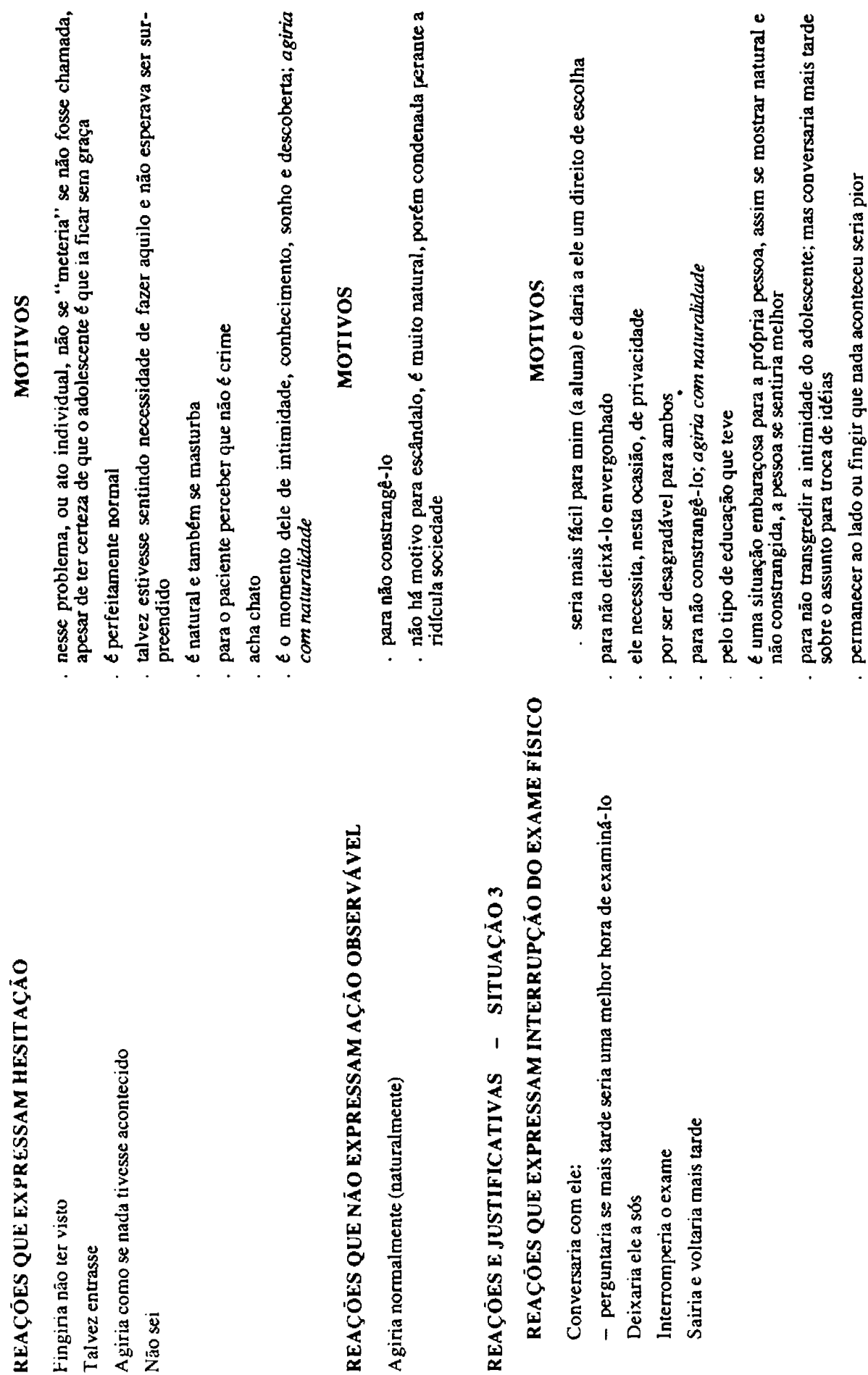

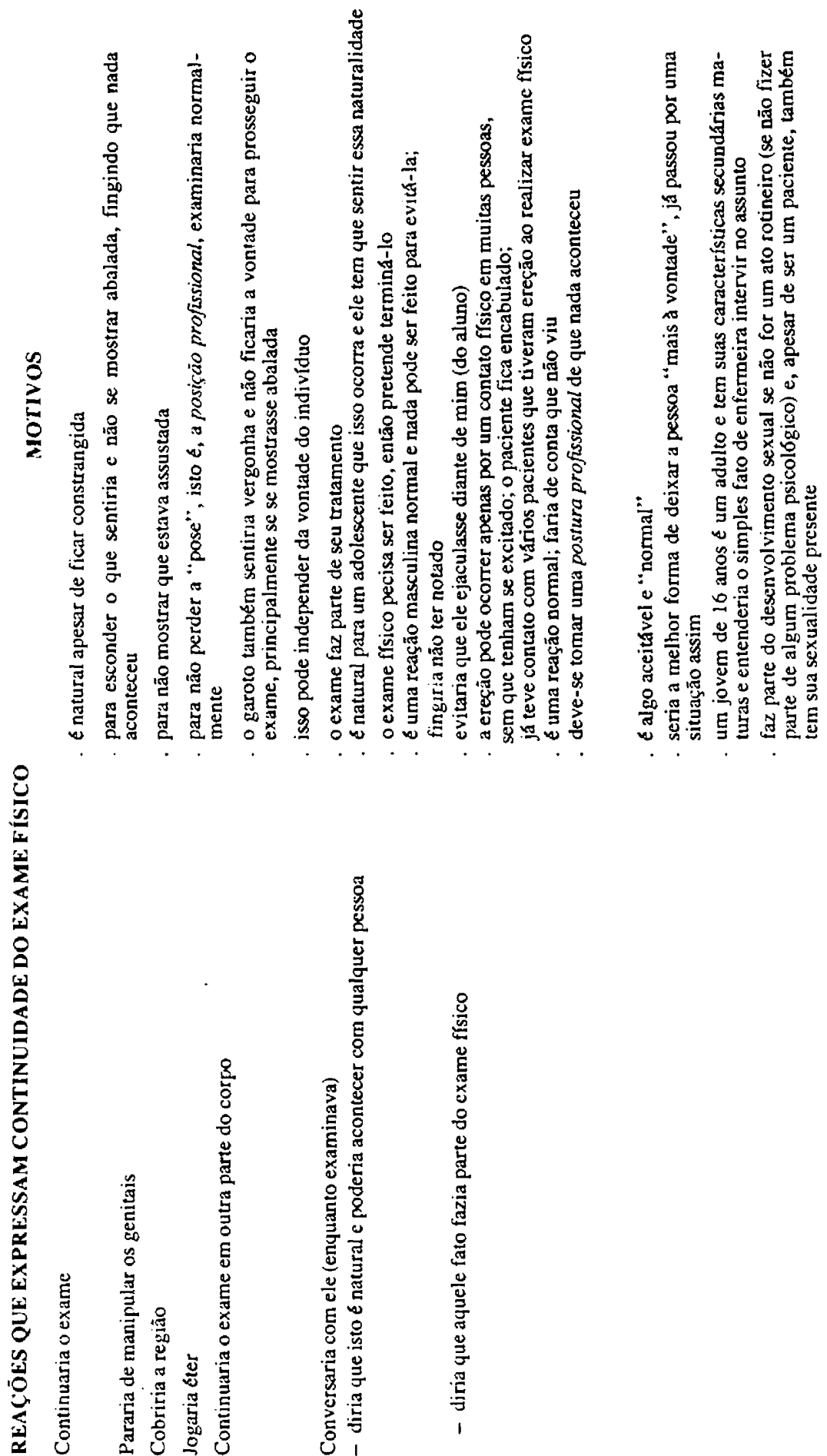

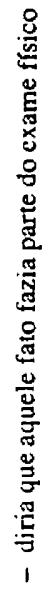

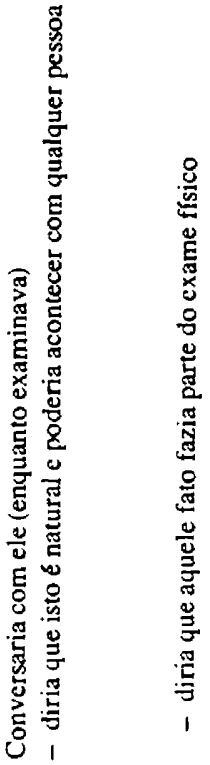

Rev. Esc. Enf. USP, Sāo Paulo, 23(2):3-19, abr. 1989 

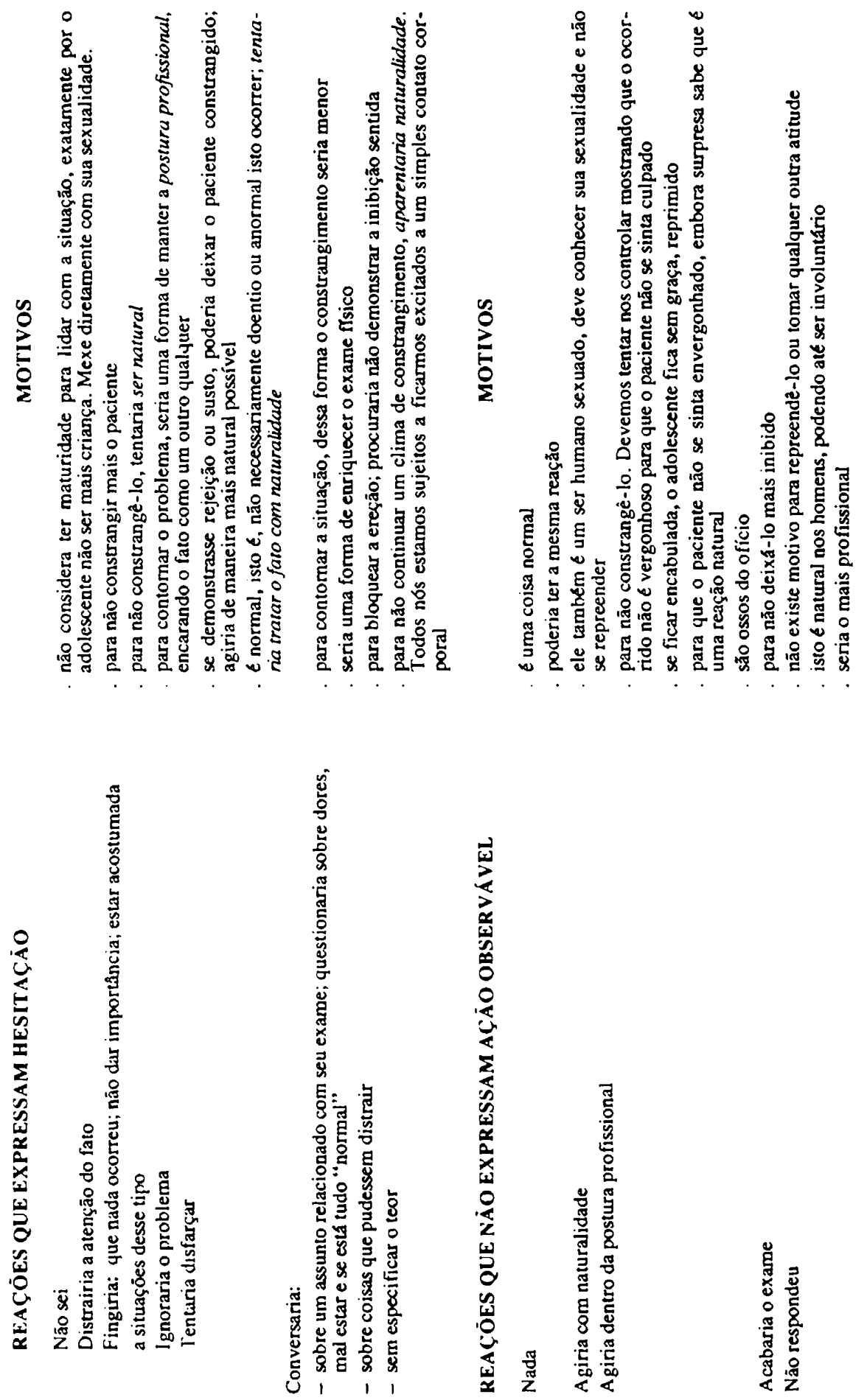